\title{
Article \\ Complexes of 1,3-Diisobutyl Thiourea with Copper(I), Zinc(II) and Mercury(II): Their Antioxidant and Antibacterial Evaluation
}

\author{
Adnan Shahzad ${ }^{1,2}$, Ezzat Khan ${ }^{1,3, * \mathbb{D}}$, Muhammad Said ${ }^{1}$, Gul Shazada Khan ${ }^{3}$, Mian Gul Syed ${ }^{1,2}$, Awal Noor ${ }^{4} \mathbb{D}_{\text {, }}$ \\ Muhammad Zahoor ${ }^{5}$ (D), Riaz Ullah ${ }^{6}$ (D) and Ahmed Bari ${ }^{7}$ (D)
}

1 Department of Chemistry, University of Malakand, Chakdara 18800, Pakistan; adnanshahzad09@gmail.com (A.S.); msaidqau@yahoo.com (M.S.); Mianguls696@gmail.com (M.G.S.)

2 Institute of Chemical Sciences, University of Swat, Swat 18800, Pakistan

3 Department of Chemistry, College of Science, University of Bahrain, Sakhir 32038, Bahrain; gulskhan79@yahoo.com

4 Anorganische Chemie II, Universität Bayreuth, 95440 Bayreuth, Germany; anoor@kfu.edu.sa

5 Department of Biochemistry, University of Malakand, Chakdara 18800, Pakistan; zahoor@uom.edu.pk

6 Department of Pharmacognosy, College of Pharmacy, King Saud University, P.O. Box 2457,

Riyadh 11451, Saudi Arabia; rullah@ksu.edu.sa

7 Department of Pharmaceutical Chemistry, College of Pharmacy, King Saud University, P.O. Box 2457, Riyadh 11451, Saudi Arabia; abari@ksu.edu.sa

* Correspondence: ekhan@uom.edu.pk

check for updates

Citation: Shahzad, A.; Khan, E.; Said, M.; Khan, G.S.; Syed, M.G.; Noor, A.; Zahoor, M.; Ullah, R.; Bari, A.

Complexes of 1,3-Diisobutyl Thiourea with Copper(I), Zinc(II) and Mercury(II): Their Antioxidant and Antibacterial Evaluation. Crystals 2021, 11, 989. https://doi.org/ $10.3390 /$ cryst11080989

Academic Editor: Marian Valko

Received: 19 July 2021

Accepted: 18 August 2021

Published: 20 August 2021

Publisher's Note: MDPI stays neutral with regard to jurisdictional claims in published maps and institutional affiliations.

Copyright: (c) 2021 by the authors. Licensee MDPI, Basel, Switzerland. This article is an open access article distributed under the terms and conditions of the Creative Commons Attribution (CC BY) license (https:// creativecommons.org/licenses/by/ $4.0 /)$.
Abstract: The reaction of 1,3-Diisobutyl thiourea (Tu) with metal salts, $\left\{[\mathrm{CuX}(\mathrm{X}=\mathrm{Cl}, \mathrm{I})],\left[\mathrm{ZnCl}_{2}\right]\right.$ and $\left[\mathrm{HgI}_{2}\right]$ in an appropriate stoichiometric ratio afforded the corresponding metal complexes $\left[\mathrm{Tu}_{2} \mathrm{CuCl}\right]$ (1), [ $\left.\mathrm{Tu}_{3} \mathrm{CuI}\right](2),\left[\mathrm{Tu}_{2} \mathrm{ZnCl}_{2}\right]$ (3) and $\left[\mathrm{Tu}_{2} \mathrm{HgI}_{2}\right]$ (4) in good yields. The FT-IR data show typically broad signals (3278-3288 $\mathrm{cm}^{-1}$ ) attributed to the involvement of $\mathrm{NH}$ bonds in extensive hydrogen bonding. The structures of complexes were proposed based on a spectroscopic data set. Compounds $\mathbf{1}$ and $\mathbf{2}$ were additionally characterized by single-crystal X-ray analysis. Complexes 1-4 were tested for their free radical scavenging efficiency using 2,2-diphenyl-1-picrylhydrazyl free radical (hereafter abbreviated as DPPH). The free radical scavenging activity was a function of decrease in the resultant absorption of DPPH solution after the mixing of an appropriate concentration of the respective complex. The activity of complexes was determined to be dose dependent and increased concentration of the complex resulted in improved antioxidant activity. Compound $\mathbf{1}$ was found to be the most efficient, with $79.9 \%$ free radical scavenging activity. Complexes were also tested for their efficiency against selected strains of bacteria (E. coli, S. flexneri, S. typhi, and P. aeruginosa) and the activities were compared to commercially available standard drug cephradine. Compound 1 was more active against $P$. aeruginosa (ZI 13.25), while compound 4 was found to be more active against E. coli (ZI 11.0), S. flexneri (ZI 11.2), and S. typhi (ZI 10.5).

Keywords: antioxidant activity; antibacterial efficiency; diisobutylthiorea; metal complexes

\section{Introduction}

Thiourea derivatives make a versatile group of compounds, with applications in organic, coordination, and material chemistry [1,2]. These compounds act as organocatalysts in a variety of reactions which lead to outstanding products [3-6]. There are two potential functional groups in thiourea derivatives, the $\mathrm{C}=\mathrm{S}$ and $\mathrm{NH}$ groups. These sites provide interesting coordination modes and make thiourea derivatives very attractive candidates for several applications. The NH function is mainly responsible for the establishment of $\mathrm{H}$-bonding and is able to make these compounds usable as sensors $[7,8]$. The $\mathrm{C}=\mathrm{S}$ function has also been effectively used for sensor applications of metal ions (cations) $[9,10]$ and has a very rich coordination chemistry with late transition metals $[11,12]$. Since the discovery 
of cisplatin, coordination compounds have been in use against various ailments. Thus, the design and synthesis of coordination compounds has continued to remain a hot topic. The two main segments in the designing of a coordination compound for biological function are the ligand and the metal ion. The selection of the ligand is made on its coordination ability to afford stable synthons, the least toxicity and easy accessibility. Metal ions should be biologically acceptable, and their complex is supposed to tolerate physiological conditions for better efficiency. Since thiourea is the active part of bioorganic chemistry for a handsome number of applications, its selection as a ligand raises no question [13-16]. Complexes with late transition metals, such as $\mathrm{Zn}$ and $\mathrm{Hg}$, possess photoluminescence properties and applications in nonlinear optics [17-19]. Complexes with $\mathrm{Cu}$ and $\mathrm{Zn}$ have been synthesized and tested in the field of bioinorganic chemistry [20-23]. The wide range of biological activities of thiourea complexes such as antimicrobial, pesticidal, herbicidal, rodenticidal, and anticancer exponentially increases the importance of these compounds. The modification of properties in a desired direction such as hydrophobicity, biocompatibility, and the potency of compounds can be varied by changing the nature and size of certain substituents.

Recently, we reported $\mathrm{Cu}$ complexes stabilized by monodentate non-thiourea ligands bearing coordination numbers $(\mathrm{CN})$ four [24,25] and six [26,27], where steric bulk and/or $\mathrm{M}-\mathrm{X}$ fragment $(\mathrm{X}=$ halogen, $\mathrm{AcO})$ played a vital role in coordination around the metal ion. These complexes with thiourea ligands $[28,29]$ showed better biological activities. Thus, we extended our studies and treated the thiourea ligand with $\mathrm{Cu}(\mathrm{I})$ metal salts, where halogen function was found responsible for defining the $\mathrm{CN}$ of the metal ion. Under identical conditions, $\mathrm{Zn}$ and $\mathrm{Hg}$ afforded the proposed complexes. Besides structural studies, these complexes were evaluated for their antioxidant and antibacterial efficiency.

\section{Experimental Section}

\subsection{General and Spectroscopy}

The handling of chemicals and other reagents was carried out under aerobic conditions. Solvents were distilled prior to use. The ligand was prepared by a literature procedure [30] and analytical-grade metal salts $\mathrm{CuI}, \mathrm{CuCl}, \mathrm{ZnCl}_{2}$ and $\mathrm{HgCl}_{2}$ were purchased from TCI, Japan, or Sigma Aldrich and were used as received. The ${ }^{1} \mathrm{H}$ - and ${ }^{13} \mathrm{C}-\mathrm{NMR}$ spectra (for ca. 5-10\% solutions) were recorded by VARIAN INOVA $300 \mathrm{MHz}$ in deuterated chloroform at room temperature. Chemical shifts are given relative to TMS $\left({ }^{1} \mathrm{H}\left(\mathrm{CHCl}_{3}\right)=7.26\right.$ and $\left.\delta^{13} \mathrm{C}\left(\mathrm{CHCl}_{3}\right)=77.16 \mathrm{ppm}\right)$. FT-IR spectra of complexes were recorded by the SHIMADZU model 8400s as KBr pellets, in the range $4000-400 \mathrm{~cm}^{-1}$. The EIMS analyses were carried out with the help of a FOCUS DSQ (thermo) mass spectrometer and the $\mathrm{m} / \mathrm{z}$ refer to isotopes ${ }^{1} \mathrm{H}$ and ${ }^{12} \mathrm{C},{ }^{14} \mathrm{~N}$, and ${ }^{63} \mathrm{Cu}$. The crystal structure of complex $\mathbf{1}$ and $\mathbf{2}$ was determined by STOE IPDSII, fitted with a low-temperature unit. In both experiments/diffractometers, Mo-Ka source with $\lambda=0.71073 \AA$ was used. Crystal structure refinements and solutions were accomplished by software SIR97, SHELXL97, WinGX, and PLATON [31-35].

\subsection{Synthesis of Compounds $\mathbf{1 - 4}$}

For the synthesis of compound 1, a solution of $\mathrm{CuCl}(0.0501 \mathrm{~g}, 0.51 \mathrm{mmol})$ was prepared in acetonitrile and was kept stirring for $2 \mathrm{~h}$, followed by the dropwise addition of 1,3-diisobutyl thiourea $(0.2802 \mathrm{~g}, 1.49 \mathrm{mmol}$, solution in acetonitrile) over a time of ca. $10 \mathrm{~min}$. The color of the resultant solution turned from yellow to colorless which indicated the reaction was complete. Stirring of the reaction mixture was continued for $12 \mathrm{~h}$, in order to ensure maximum product formation. The reaction mixture was filtered for the separation of unreacted salt and other insoluble material and the filtrate was kept for slow evaporation at room temperature. Colorless crystals of the desired compound $\mathbf{1}$ appeared after a few days and were separated from the mother liquor, then studied with the help of EI-MS, UV/Vis spectroscopy, FT-IR, and X-ray diffraction. Following the same procedure, compound 2 was prepared by treating $\mathrm{CuI}(0.0500 \mathrm{~g}, 0.26 \mathrm{mmol})$ and the ligand $(0.148 \mathrm{~g}, 0.79 \mathrm{mmol})$ together; colorless block crystals were grown after 6 days. Compound 3 was obtained by treating $\mathrm{ZnCl}_{2}(0.0602 \mathrm{~g}, 0.44 \mathrm{mmol})$ with the ligand 
(0.167 $\mathrm{g}, 0.89 \mathrm{mmol})$, using $\mathrm{MeOH}$ as solvent. Colorless crystals appeared after 2 days, were separated and then studied. Compound 4 was prepared in the same way, with $\mathrm{HgI}_{2}$ $(0.2407 \mathrm{~g}, 0.529 \mathrm{mmol})$ and the ligand $(0.2003 \mathrm{~g}, 1.06 \mathrm{mmol})$ in $\mathrm{MeOH}$.

Complex 1, bis(1,3-Diisobutylthiourea)copper(I) chloride: Yield: $60 \% ; \mathrm{C}_{18} \mathrm{H}_{40} \mathrm{~N}_{4} \mathrm{ClS}_{2} \mathrm{Cu}$; Found (Cal): C 45.54 (45.45), H 8.36 (8.48), N 12.06 (11.78); EI-MS: m/z (\%) 188 (99) Tu, 255 (85) Cu-Tu, 96 (25) Cu-Cl; FT-IR (KBr) $v\left(\mathrm{~cm}^{-1}\right)=3280 \mathrm{br}, 2965 \mathrm{~s}, 2878 \mathrm{~s}, 1734 \mathrm{~s}$.

Complex 2, tris(1,3-diisobutyl thiourea)copper(I) iodide: Yield: $65 \% ; \mathrm{C}_{27} \mathrm{H}_{60} \mathrm{~N}_{6} \mathrm{IS}_{3} \mathrm{Cu}$; Found (Cal): C 38.47 (40.93), H 7.18 (8.01), N 10.65(11.12); MS (+ESI): m/z 188 (99) Tu, 254 (45) Cu-Tu, 380 (20) I-Cu-Tu; FT-IR (KBr) $v\left(\mathrm{~cm}^{-1}\right)=3288 \mathrm{br}, 2971 \mathrm{~s}, 2882 \mathrm{~s}, 1751 \mathrm{~s}$.

Complex 3, bis(1,3-diisobutylthiourea)zinc(II) chloride: Yield: $76 \% ; \mathrm{C}_{18} \mathrm{H}_{40} \mathrm{~N}_{4} \mathrm{Cl}_{2} \mathrm{~S}_{2} \mathrm{Zn}$; Found (Cal): C 40.61 (42.15), H 7.39 (7.86), N 10.43 (10.92); ${ }^{1}$ H-NMR (300 MHz, CDCl 3 ) $\delta(\mathrm{ppm})=0.95(\mathrm{br}, \mathrm{Me}), 1.96(\mathrm{br}, \mathrm{CH}), 3.36\left(\mathrm{br}, \mathrm{CH}_{2}\right), 6.06(\mathrm{br}, \mathrm{NH}):{ }^{13} \mathrm{C}-\mathrm{NMR}(75.8 \mathrm{MHz}$, $\left.\mathrm{CDCl}_{3}\right) ; \delta(\mathrm{ppm})=20.2(\mathrm{Me}), 28.3(\mathrm{CH}), 52.4\left(\mathrm{~N}-\mathrm{CH}_{2}\right), 174.8(\mathrm{C}=\mathrm{S}) ; \mathrm{MS}(\mathrm{EI}): \mathrm{m} / z(\%): 188(99)$ $\mathrm{Tu}, 253$ (25) Zn-Tu; FT-IR (KBr) $v\left(\mathrm{~cm}^{-1}\right)=3278 \mathrm{br}, 2956 \mathrm{~s}, 2868 \mathrm{~s}, 1748 \mathrm{~s}$.

Complex 4, bis(1,3-diisobutylthiourea)mercury(II) iodide: Yield: $79 \% ; \mathrm{C}_{18} \mathrm{H}_{40} \mathrm{~N}_{4} \mathrm{l}_{2} \mathrm{~S}_{2} \mathrm{Hg}$; Found (Cal): C 26.24 (26.01), H 5.6 (4.85), N 7.57 (6.74); ${ }^{1} \mathbf{H}-\mathbf{N M R}\left(300 \mathrm{MHz}, \mathrm{CDCl}_{3}\right)$ $\delta(\mathrm{ppm})=0.97\left(\mathrm{~d}, 24 \mathrm{H}, \mathrm{Me}, J\left({ }^{1} \mathrm{H},{ }^{1} \mathrm{H}\right)=6.63 \mathrm{~Hz}\right), 2.01\left(\mathrm{Sep}, 4 \mathrm{H}, \mathrm{CH}, J\left({ }^{1} \mathrm{H},{ }^{1} \mathrm{H}\right)=6.67\right), 3.21$ (br, 8H, CH 2$), 5.80(\mathrm{br}, 4 \mathrm{H}, \mathrm{NH}) ;{ }^{13} \mathrm{C}-\mathrm{NMR}\left(75.8 \mathrm{MHz} \mathrm{CDCl}_{3}\right) ; \delta(\mathrm{ppm})=20.5(\mathrm{Me}), 27.9$ (CH), $51.9\left(\mathrm{~N}_{-} \mathrm{CH}_{2}\right), 176.9$ (C=S); MS(EI): m/z (\%) 188 (99) Tu, 328 (7) HgI, 456 (35) $\mathrm{HgI}_{2}$; FT-IR $(\mathrm{KBr}) v\left(\mathrm{~cm}^{-1}\right)=3281 \mathrm{br}, 2961 \mathrm{~s}, 2872 \mathrm{~s}, 1741 \mathrm{~s}$.

\subsection{Determination of Antioxidant Potentials}

$\mathrm{DPPH}$ is a stable free radical and is capable of utilizing its unpaired electron in a chemical interaction with any other species. The involvement of this unpaired radical with foreign species is a function of free radical scavenging of that species/compound. Compounds 1-4 were tested for their antioxidant activities against DPPH. A solution containing $0.039 \mathrm{~g} / 100 \mathrm{~mL}$ of DPPH was prepared and used as a standard/control. Absorbance of this solution was measured at $517 \mathrm{~nm}$ under normal conditions of temperature. After mixing the solution of the respective compound with DPPH solution, a change in the resultant absorbance was observed. The decrease in maximum absorbance of the solution was taken as a function of the compound. Prior to the determination of absorbance, all solutions were incubated in the dark for $30 \mathrm{~min}$ at room temperature $\left(23 \pm 1^{\circ} \mathrm{C}\right)$. The percent inhibition capacity of each complex (I)\%, was calculated as below [36].

$$
\text { Perecent Inhibition } \mathrm{I} \%=\frac{A_{D P P H}-A_{\text {sample }}}{A_{D P P H}} \times 100
$$

\subsection{Antibacterial Screenings of Selected Compounds}

The agar well diffusion assay was used to evaluate antimicrobial potentials of complexes 1-4 [37,38]. Sterile, nutrient agar was prepared and poured in Petri dishes. Bacterial cultures were evenly applied on the surface of the agar Petri dishes by sterile swab sticks. Wells of $6 \mathrm{~mm}$ diameter were bored (five per plate) with a sterile borer. An amount of $6.25 \mathrm{mg} / \mathrm{mL}$ of each compound was applied to each well. The commercially available antibiotic cephradine was used for comparing the efficiency of each complex. For the sake of accuracy, the same concentration of each complex and the standard was applied. The agar plates were covered with lids and were incubated at $37 \pm 1^{\circ} \mathrm{C}$ for $24 \mathrm{~h}$ in an oven. Growth inhibition was observed in each bore and the respective zones were measured manually. The diameter of the zones of inhibition is a measure of antimicrobial activity of the corresponding complex. The data presented for antibacterial activity are the average diameter of the zones of inhibition in $\mathrm{mm}$. 


\section{Results and Discussion}

\subsection{General Chemistry and Spectroscopy}

The proposed structures of compounds and the corresponding ligand (inserted) are shown in Scheme 1. The treatment of ligand (1,3-diisobutylthiourea) with copper(I) chloride in molar ratio 3:1, respectively, afforded Complex 1 . The reaction of $\mathrm{CuCl}$ with a two-fold excess of the ligand was carried out under identical conditions and the same products were obtained. By changing the reaction medium from acetonitrile to $\mathrm{MeOH}$, all attempts were unsuccessful in obtaining exclusively tetrahedral complex of geometry $\left[\mathrm{CuL}_{3} \mathrm{Cl}\right]$, $\left[\mathrm{CuL}_{2} \mathrm{Cl}_{2}\right]$, or $\left[\mathrm{CuL}_{4}\right] \mathrm{Cl}$, where $\mathrm{L}=$ thiourea ligand [39-41]. The ligand reacted with $\mathrm{CuI}$ in a molar ratio 3:1 and the proposed compound 2 was thus obtained. These observations reveal that the presence of halogen function can affect the coordination sphere around the metal ion. The reaction of the ligand with $\mathrm{Zn}$ and $\mathrm{Hg}$ metal ions was straightforward, as was reported for structurally analogous species [42].

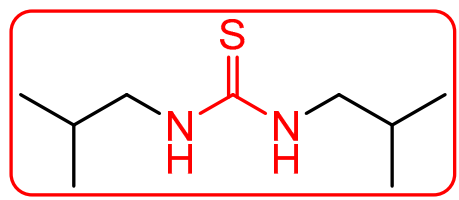

Ligand (L)

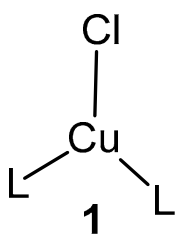

1

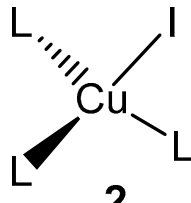

2
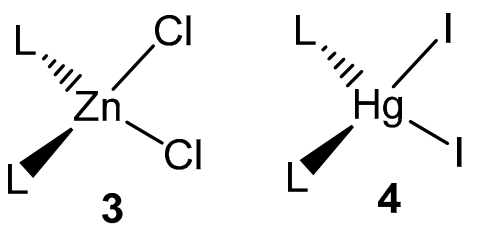

Scheme 1. Structures of ligand (left inserted) and its corresponding complexes with $\mathrm{Cu}, \mathrm{Zn}$ and $\mathrm{Hg}$ ions.

Complexes 1-4 were obtained as crystalline material from their respective reaction mixtures and structures of complexes were deduced from a consistent set of spectroscopic data. The FT-IR spectra of all compounds contain typically broad signals $\left(3278-3288 \mathrm{~cm}^{-1}\right.$ ) that correspond to the involvement of $\mathrm{NH}$ bonds in extensive hydrogen bonding. NMR spectroscopy is a reliable technique in the structural elucidation of compounds and is of particular importance in coordination chemistry, where the coordination behavior of thiourea ligands can easily be determined to be an $\mathrm{N}$ or $\mathrm{S}$ donor. The ${ }^{1} \mathrm{H}-\mathrm{NMR}$ of complex 3 and 4 show distinct typically broad signals at 4.01 and $3.47 \mathrm{ppm}$, respectively, which can be assigned unambiguously to NH group. These signals show considerable shift with respect to the free ligand (5.89 ppm, given in supporting information). The ${ }^{13} \mathrm{C}-\mathrm{NMR}$ process is quite useful in this regard: the $C=S$ signal appeared at $181.7 \mathrm{ppm}$ in the free thiourea ligand and was found to be considerably shifted in complex 3 and 4 to 174.8 and 176.9 ppm, respectively. These data indicate the bond formation through the $S$ atom, thus affording the proposed coordination behavior of the TU ligand [43]. The mass fragmentation pattern of compounds 1-3 was also studied using the EI-MS technique. The information retrieved from these data were not too informative because of the high-energy ionization technique. All the complexes gave a base peak at $\mathrm{m} / \mathrm{z} 188$, which corresponds to the ion of the thiourea ligand. A molecular ion peak for these complexes was not observed.

\subsection{Structural Description of Complex $\mathbf{1}$}

Ethyl fragments in the structure of compound $\mathbf{1}$ (shown in Figure 1) suffer from some sort of disorder which makes it very difficult to precisely solve and refine the structure. The diffraction data provide enough information which is sufficient for the establishment of connectivity. The reaction of the ligand with $\mathrm{CuCl}$ in molar ratio 3:1 exclusively afforded compound 1. The molecule is monoclinic, bearing space group Cc (further details pertaining to refinements and crystal structure solution are summarized in Table 1). The geometry around the metal ion is trigonal planar. Two thiourea ligands are attached to the metal ion through the $S$ atom, which is normal behavior of thiourea derivatives [28]. Bond angles around the metal ion are $115.76(13)^{\circ},(\mathrm{S} 1-\mathrm{Cu} 1-\mathrm{S} 2), 120.94(11)^{\circ}$, and $123.30(12)^{\circ}$ (S1-Cu1-C1 and S2-Cu1-Cl, respectively). The sum of all three angles around metal ion is $360^{\circ}$, which clearly supports the trigonal environment. The $\mathrm{Cu}-\mathrm{S}$ bond lengths with 
negligible difference, 2.213(4) and 2.216(3) $\mathrm{A}$, are shorter than the $\mathrm{Cu}-\mathrm{Cl}$ bond (2.272(3) $\mathrm{A})$ and are within the expected limit [44] (Table 2). Coordination with the metal ion through $S$ reduces the bond order between $C$ and $S$; therefore, it results in $C=S$ bond elongation as compared to the uncoordinated thiourea derivative and are comparable to structurally analogous compounds $[28,30,45,46]$. A close view of molecules of complex $\mathbf{1}$ in solid state reveals that chloro function is actively involved in intra- as well as intermolecular secondary interactions. The intramolecular separation distance between $\mathrm{N} 4 \cdots \mathrm{Cl}$ is $3.268 \AA$, and the (intermolecular) $\mathrm{Cl} \cdots \mathrm{N} 3$ distance is $3.268 \AA$ (Figure 2). The difference in bond lengths, C1-N3 1.306(14) and C1-N4 1.349(14) $\AA$, can possibly be explained on the basis of intramolecular interactions wherein $\mathrm{N}$ atoms of one coordinated thiourea ligand are involved (Figure 2). Each molecule offers an N3 of a coordinated ligand to participate in secondary interactions, which is the probable reason for slightly different $\mathrm{C}-\mathrm{N}$ bond lengths.

Table 1. Crystal structure solution and refinement parameters of complexes $\mathbf{1}$ and $\mathbf{2}$.

\begin{tabular}{|c|c|c|}
\hline Compound & 1 & 2 \\
\hline Empirical formula & $\mathrm{C}_{36} \mathrm{H}_{80} \mathrm{Cl}_{2} \mathrm{Cu}_{2} \mathrm{~N}_{8} \mathrm{~S}_{4}$ & $\mathrm{C}_{27} \mathrm{H}_{60} \mathrm{~N}_{6} \mathrm{CuIS}_{3}$ \\
\hline Formula weight & 951.30 & 755.43 \\
\hline Temperature (K) & 296 & 133 \\
\hline Crystal system & Monoclinic & Trigonal \\
\hline Space group & $\mathrm{Cc}$ & P-3 \\
\hline $\mathrm{a}, \AA$ & $19.675(5)$ & $13.592(7)$ \\
\hline $\mathrm{b}, \AA$ & $12.226(5)$ & $13.592(7)$ \\
\hline c, $\AA$ & $10.772(8)$ & 11.254(5) \\
\hline B,deg & $95.04(5)$ & 90 \\
\hline Volume $\AA^{3}$ & 2581.2(13) & $1800.5(2)$ \\
\hline $\mathrm{Z} / \mathrm{Z}^{\prime}$ & $2 / 0.5$ & $2 / 0.5$ \\
\hline$\mu\left(\mathrm{mm}^{-1}\right)$ & 1.12 & 1.66 \\
\hline$F(000)$ & 1016 & 788 \\
\hline Wavelength (̊) & 0.71069 & 0.71069 \\
\hline Diffractometer & STOE-IPDSII & STOE-IPDSII \\
\hline$\theta_{\min }-\theta_{\max }, \operatorname{deg}$ & $1.963-26.240$ & $1.730-26.174$ \\
\hline Range of indices & $-24 \leq h \leq 24$ & $-16 \leq h \leq 16$ \\
\hline & $-15 \leq k \leq 15$ & $-16 \leq k \leq 16$ \\
\hline & $-13 \leq l \leq 13$ & $-13 \leq l \leq 13$ \\
\hline Total number of reflections & 17780 & 25350 \\
\hline $\mathrm{R}_{\text {int }}$ & 0.123 & 0.048 \\
\hline Completeness of data to $\theta_{\max }, \%$ & 99.4 & 99.7 \\
\hline$T_{\max } / T_{\min }$ & None & $0.813 / 0.915$ \\
\hline Number of observed reflections $(I>2 \sigma(I))$ & 2450 & 2238 \\
\hline Number of refined parameters & 243 & 127 \\
\hline Goodness of Fit & 0.844 & 1.088 \\
\hline Crystal size & $0.26 \times 0.19 \times 0.14$ & $0.28 \times 0.27 \times 0.13$ \\
\hline $\mathrm{R}((I>2 \sigma(I))$ & $\begin{array}{c}R_{1}=0.0586 \\
w R_{2}=0.1176\end{array}$ & $\begin{array}{c}R_{1}=0.0279 \\
w R_{2}=0.0683\end{array}$ \\
\hline $\mathrm{R}$ for all reflections & $\begin{array}{c}R_{1}=0.1411 \\
w R_{2}=0.1418\end{array}$ & $\begin{array}{c}R_{1}=0.0301 \\
w R_{2}=0.0713\end{array}$ \\
\hline Residual electron density (max/min), (e/ $\left.\AA^{3}\right)$ & $0.46 /-0.39$ & $0.80 /-0.59$ \\
\hline
\end{tabular}


Table 2. Selected bond lengths $(\AA)$ and angles $\left(^{\circ}\right)$ of structures 1 and 2.

\begin{tabular}{ccccc}
\hline Compound & Atoms & Bond Length & Atoms & Angles \\
\hline & Cu1-S2 & $2.213(4)$ & S2-Cu1-S1 & $115.76(13)$ \\
Cu1-S1 & $2.216(3)$ & S2-Cu1-Cl & $123.30(12)$ \\
& Cu1-C1 & $2.272(3)$ & S1-Cu1-Cl & $120.94(11)$ \\
& S1-C1 & $1.736(12)$ & N3-C1-N4 & $121.4(10)$ \\
N3-C1 & $1.306(14)$ & N3-C1-S1 & $120.5(9)$ \\
& N4-C1 & $1.349(14)$ & N4-C1-S1 & $118.0(8)$ \\
& N2-C11 & $1.342(15)$ & N1-C11-N2 & $117.6(10)$ \\
& N1-C11 & $1.337(14)$ & N1-C11-S2 & $122.1(10)$ \\
& I1-Cu1 & $2.610(5)$ & S1-Cu1-S1 & $100.32(2)$ \\
& Cu1-S1 & $2.336(6)$ & S1-Cu1-I1 & $117.55(16)$ \\
& S1-C1 & $1.713(2)$ & C1-S1-Cu1 & $112.72(7)$ \\
& N1-C1 & $1.329(3)$ & N1-C1-N2 & $118.08(19)$ \\
& N1-C2 & $1.456(3)$ & N1-C1-S1 & $120.88(19)$ \\
& N2-C1 & $1.335(3)$ & N2-C1-S1 & $120.03(16)$ \\
& N2-C6 & $1.456(3)$ & & \\
\hline
\end{tabular}

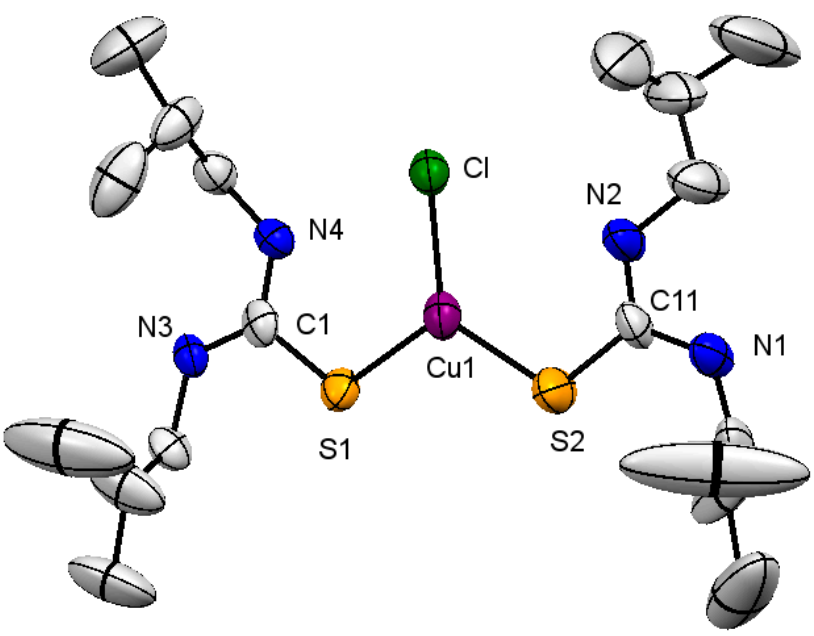

Figure 1. Molecular structure of Complex 1, ball and stick representation with partial numbering scheme. All hydrogen atoms are omitted for clarity, summarized bond lengths $(\AA)$ and angles $\left(^{\circ}\right)$ are shown in Table 2. Two of the ethyl groups show disorder, which is the reason for relatively large displacement parameters and unusual bond distances (C21A-C51 1.08(3), C21A-C32 1.68(4) and C14-C35 1.29(3) ̊).

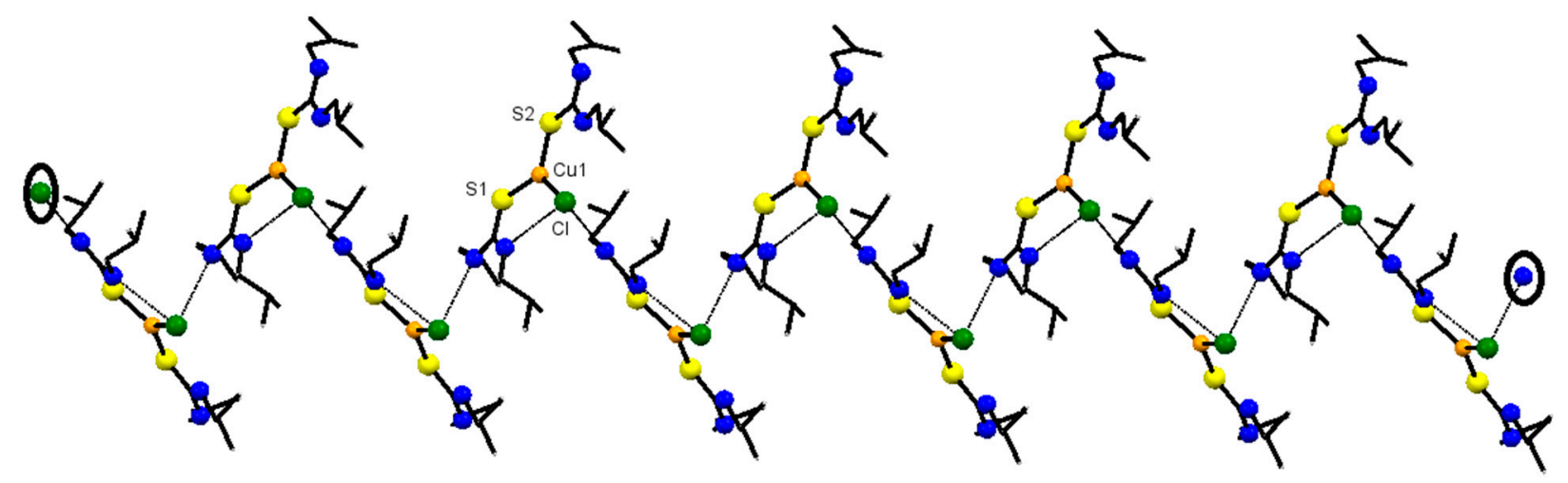

Figure 2. 1D representation of Complex 1, the infinite pseudo-polymeric zigzag chain stabilized by intermolecular $\mathrm{NH} \cdot \mathrm{Cl}$ interactions. Hydrogen atoms are omitted for clarity and hanging contacts at both ends of the chain are encircled to make them prominent. Intramolecular $\mathrm{NH} \cdots \mathrm{Cl}$ interactions are also indicated. 


\subsection{Structural Description of Complex 2}

The structure of complex 2 is depicted in Figure 3, together with selected bond lengths and angles. The structure solution and refinements were carried out as per details given in Table 1. The crystal structure is trigonal with space group $\mathrm{P}-3$. The $\mathrm{Cu}^{+}$ion is surrounded by three thiourea ligands and a halogen (iodide), making the tetrahedral geometry with expected deviation owing to hetero-ligands [47,48]. The ligand is attached through the $\mathrm{S}$ atom, as normally expected for this class of compounds. The angles S1-Cu1S1 and S1-Cu1-I1 are 100.32(2) and 117.55(16), respectively, with the sum of all six angles amounting to $653.6^{\circ}$, which supports distorted tetrahedral geometry around the metal ion [49]. These features are within the expected limit and are very close to structurally analogous complexes [50,51]. The M-S bond distance of 2.336(6) $\AA$ for complex 2 is within the expected limit for analogous thiourea complexes [41]. The $\mathrm{C}=\mathrm{S}$ bond slightly elongates (1.713(2) $\AA$ ) with respect to the uncoordinated ligand (1.698 $\AA$ ) because of electronic flow towards the metal ion. The abovementioned behavior of the ligand causes an electron delocalization over the S-C-N fragment $[1,52]$. There are a number of secondary short-range interactions within the molecules of the complex, which can be useful for further studies and in predicting certain applications of the complex. The hydrogen of $\mathrm{C} 2 \mathrm{H}$ and $\mathrm{N} 2 \mathrm{H}$ of each ligand are involved in interactions with $\mathrm{S}$ atoms of neighboring molecules. Each $\mathrm{S}$ atom of the ligand is pseudo-four-coordinated, and the supramolecular structure of complex 2 extends in a 3D fashion.

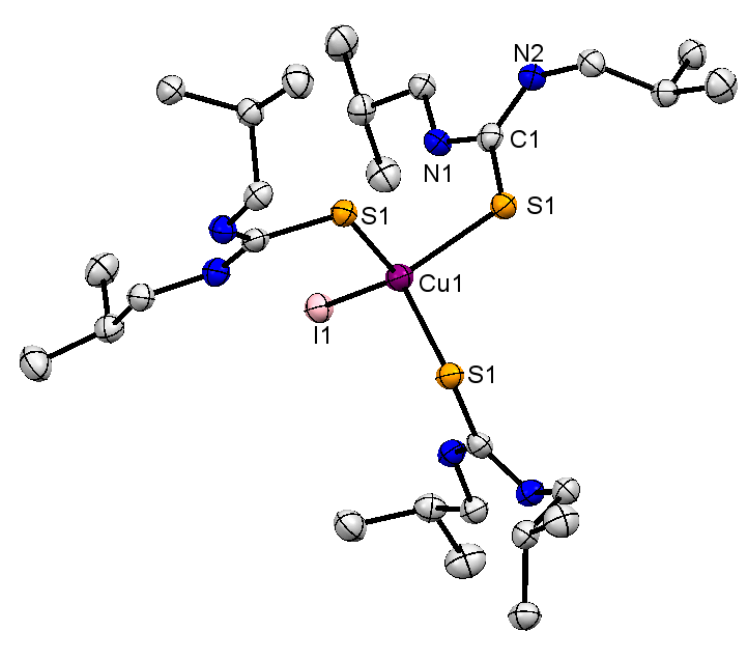

Figure 3. Molecular structure of compound 2 with partial numbering scheme. Thermal ellipsoid drawn at 50\% probability level, hydrogens are omitted for simplicity, summarized bond lengths $(\AA)$ and angles $\left(^{\circ}\right)$ are given in Table 2 .

\subsection{Free Radical Scavenging Activities of Complexes 1-4}

The inhibitory effects of thiourea complexes 1-4 were studied using DPPH as the free radical. For these complexes, which include S-coordinated 1,3-diisobutyl thiourea molecules, high antioxidant activity was discovered. The absorption intensity of DPPH was reduced by the addition of complexes 1-4, in a dose-dependent manner ranging from $00-100 \mathrm{ppm}$. The decrease in absorbance of the resultant solution was quite regular, as expected for an antioxidant reagent. The percent RSA (radical scavenging activity) of compounds was at its lowest at a lower concentration and was at its maximum at a $100 \mathrm{ppm}$ concentration of each complex, in a dose-dependent manner. A comparison of the activity of 1-4 at $100 \mathrm{ppm}$ (maximum concentration) was found to be $79.9 \%, 19.5 \%, 29.3 \%$, and $19.2 \%$, respectively, which indicates that compound $\mathbf{1}$ is more potent as compared to 2-4. Data pertaining to the free radical scavenging efficiency of complexes are summarized in Table 3 and the same are graphically described in Figure 4. The complex reveals a reasonable $\mathrm{R}^{2}$ value of 0.9453, shown in Figure 5 (see Figures S1-S6 for complexes 2, 3 and 4) (see Supplementary Materials). Among these four complexes, 1 is a far better antioxidant 
and the activity can be observed by the naked eye due to the change in the color of the solution after mixing the appropriate concentration with DPPH (Figure 6). The activity of compounds 2-4 were the least, and color change was difficult to be observed with the naked eye. The activity of compound $\mathbf{1}$ was better than the $\mathrm{Cu}$ complex stabilized by phosphine ligands, as has been reported recently [25].

Table 3. Percent free radical scavenging activities of compound 1-4.

\begin{tabular}{ccccc}
\hline Concentration $(\mathbf{p p m})$ & $\mathbf{1}$ & $\mathbf{2}$ & $\mathbf{3}$ & $\mathbf{4}$ \\
\hline 20 & 63.6 & 5.2 & 9.4 & 6.5 \\
40 & 66.7 & 13.7 & 16.8 & 12.5 \\
60 & 74.9 & 18.2 & 18.2 & 15.6 \\
80 & 78.2 & 19.2 & 27.9 & 16.0 \\
100 & 79.9 & 19.5 & 29.3 & 19.2 \\
\hline
\end{tabular}

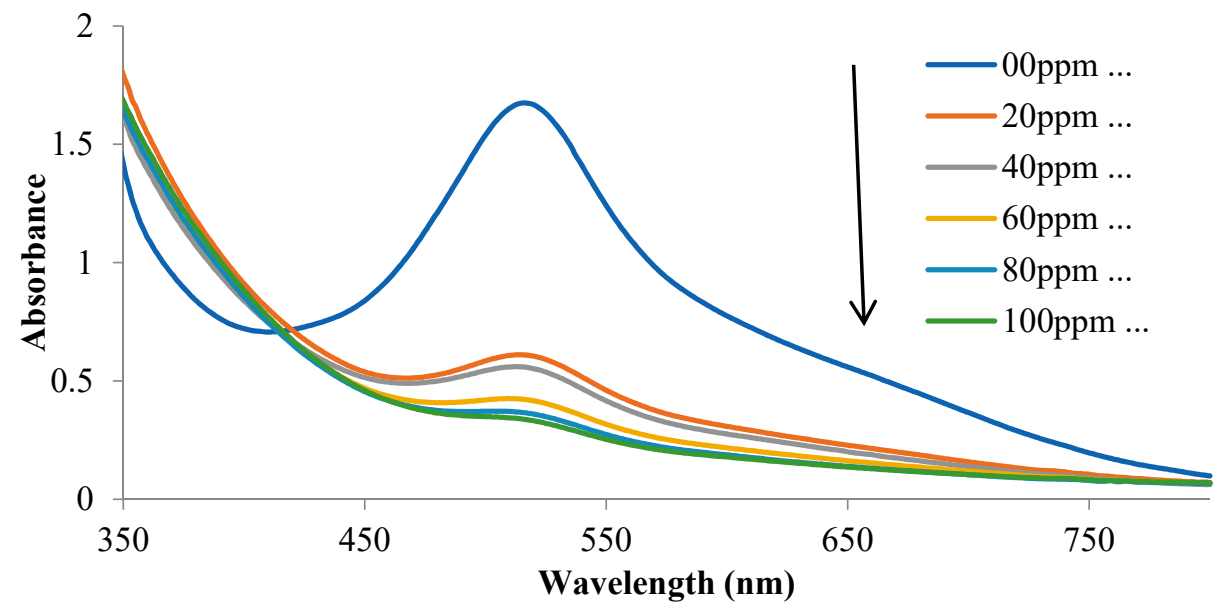

Figure 4. Absorption spectra of DPPH in the absence (top spectra) and presence of the compound 1 $(20,40,60,80$, and $100 \mathrm{ppm})$. There is abrupt drop in the absorbance of the solution by addition of the antioxidant agent (compound $\mathbf{1}$ ).

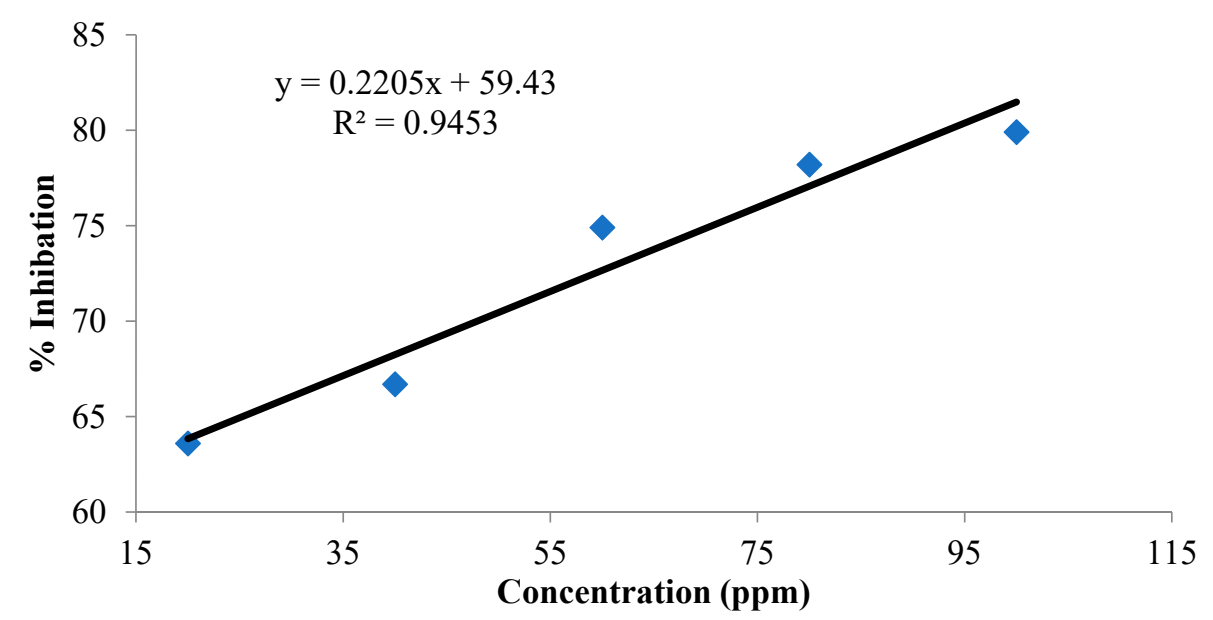

Figure 5. Graphical representation of percent inhibition versus concentration of compound 1 for radical scavenging activity. 


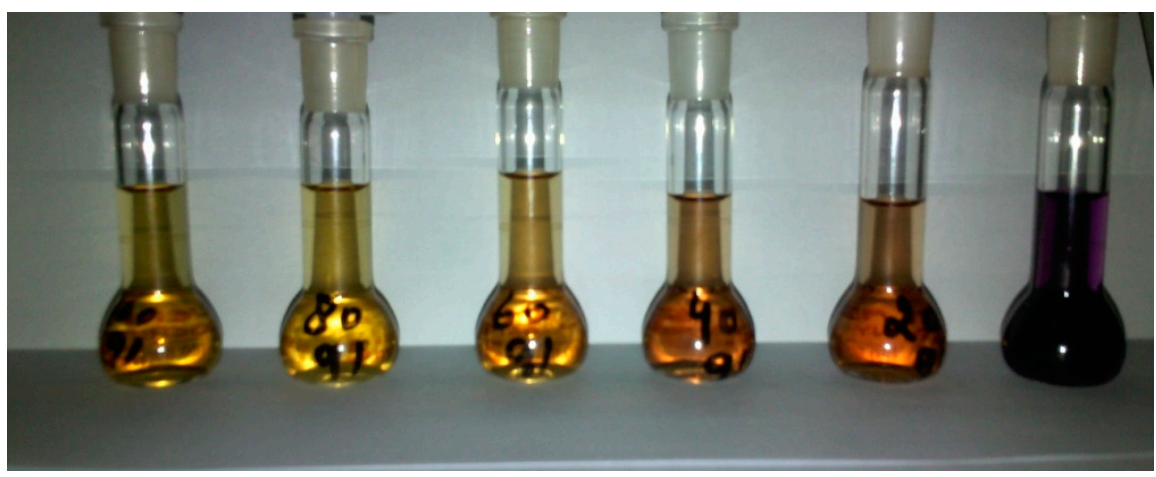

Figure 6. Naked eye detection of DPPH radical scavenging activity of compound 1. Sample flask to the right-hand side contains free DPPH, and concentration of compound $\mathbf{1}$ increases in the preceding flasks from right to left.

\subsection{Antibacterial Activity}

The agar well diffusion method was used to assess the antimicrobial activity of complexes 1-4. Escherichia coli, Shigella flexneri, Pseudomonas aeruginosa, and Salmonella typhi were selected for this study and complexes 1-4 were studied against these strains. The antibacterial evaluation of these complexes reveal that they exhibit moderate activity in comparison to cephradine. The overall inhibition range of $6.2-13.25 \mathrm{~mm}$ (Table 4) was observed for these complexes. Compound 1 shows comparatively better activity against E. coli and P. aeruginosa, comparable with standard drugs, and compound $\mathbf{4}$ is most active against three strains: E. coli, S. typhi and S. flexneri. Compounds $\mathbf{2}$ and $\mathbf{3}$ were found to be poor antibacterial agents among these four complexes. The activity of all complexes and the standard is graphically represented in Figure 7.

Table 4. Antimicrobial activities of compounds 1-4, ZI were measured in mm.

\begin{tabular}{cccccc}
\hline Bacterial Strain & $\mathbf{1}$ & $\mathbf{2}$ & $\mathbf{3}$ & $\mathbf{4}$ & Cephradine \\
\hline E. coli & 10.0 & 8.0 & 9.2 & 11.0 & 12.01 \\
S. typhi & 7.5 & 6.2 & 8.0 & 10.5 & 13.02 \\
S. flexenari & 9.0 & 7.5 & 8.7 & 11.2 & 14.50 \\
P. aeruginosa & 13.25 & 10.5 & 6.25 & 8.0 & 15 \\
\hline
\end{tabular}

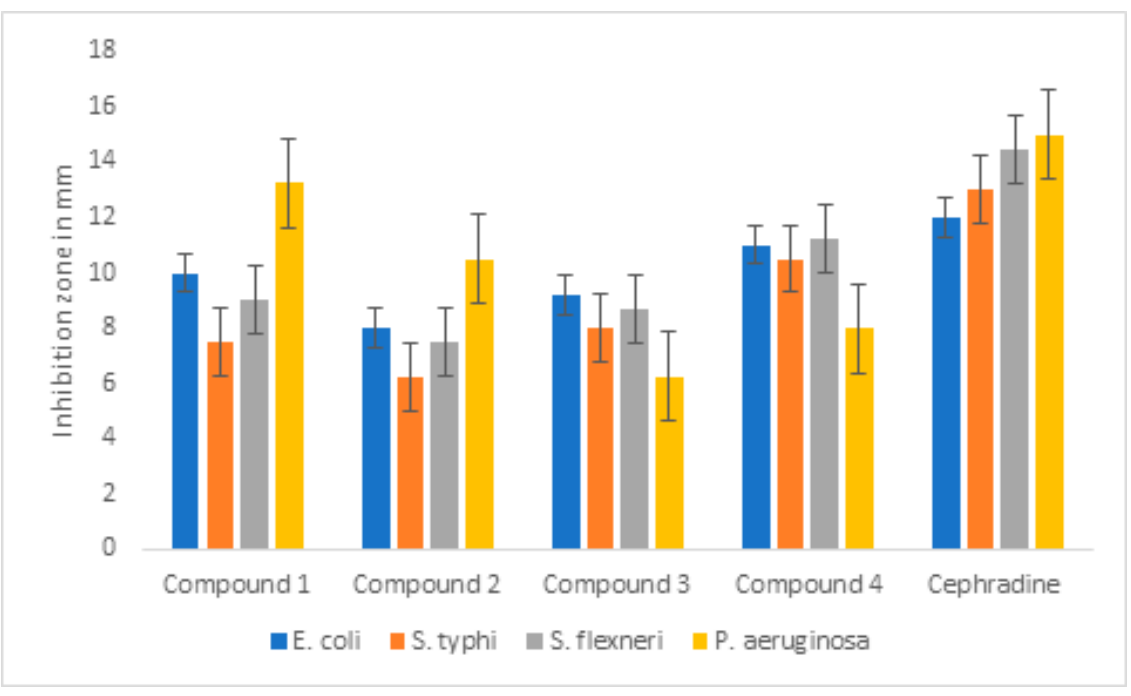

Figure 7. Graphical representation of antimicrobial activities of compounds 1-4. 


\section{Conclusions}

Four new heteroleptic transition metal complexes (1-4) were successfully obtained by reacting 1,3-diisobutyl thiourea with $\mathrm{CuCl}, \mathrm{CuI}, \mathrm{ZnCl}_{2}$, and $\mathrm{HgI}_{2}$, respectively. Despite the same reaction conditions, reaction with $\mathrm{CuCl}$ and $\mathrm{CuI}$ afforded bis-ligated and tris-ligated copper halide complexes, respectively. Compounds $\mathbf{1}$ and $\mathbf{2}$ were also characterized by single-crystal X-ray analysis. The $\mathrm{Zn}$ and $\mathrm{Hg}$ metals were included in the study with the intent to explore the coordination behavior of the ligand, and the proposed geometries were obtained. All complexes were tested for their free radical scavenging ability and antimicrobial potentials; the data reveal that compound $\mathbf{1}$ is an excellent antioxidant and the activity could be observed with the naked eye. All compounds showed antioxidant potentials in a dose-dependent manner. In comparison to the standard, compound $\mathbf{1}$ was active against $E$. coli and $P$. aeruginosa, while compound 4 was a potent antibacterial agent against $E$. coli, S. typhi and S. flexneri. Future work regarding functionalization can explore potentials of thiourea complexes as antioxidant and antibacterial reagents.

Supplementary Materials: CCDC No 1,994,970 (1) and 1,979,130 (2) contain the supplementary crystallographic data for complex 1 and 2. These data can be obtained free of charge via http: / / www.ccdc.cam.ac.uk/conts/retrieving.html accessed on 17 August 2021, or from the Cambridge Crystallographic Data Centre, 12 Union Road, Cambridge CB2 1EZ, UK; fax: (+44) 1223-336-033; or email: deposit@ccdc.cam.ac.uk. Figures S1-S6 are available online at https:/ / www.mdpi.com/article / 10.3390 / cryst11080989/s1, Figure S1. Absorption spectra of DPPH in the absence of compound 2 (Top spectra) and presence of increasing concentration of the compound (20, 40, 60, 80 \& 100 ppm). Arrow shows the change in absorption as a function of activity with respect to increasing concentration of compound 2. Figure S2. Plot of \% Inhibition versus concentration of compound 2 for radical scavenging activity. Figure S3. Absorption spectra of pure DPPH, the absorbance decreased when compounds 3 was added, in a dose dependent manner. Figure S4. Percent inhibition versus concentration of compound 3 for radical scavenging activity. Figure S5. Absorption spectra of free radical $(\mathrm{DPPH})$ in the absence (Top spectra) and presence of increased concentration of the compound 4 (20, $40,60,80 \& 100 \mathrm{ppm})$. Arrow show the change in spectra on increasing concentration of compound. Figure S6. Plot of \% Inhibition versus concentration of compound 4 for radical scavenging activity.

Author Contributions: A.S. Data curation, writing of paper original draft, E.K. Conceptualization, Data curation, Project Administration, Formal analysis; Funding acquisition; Methodology; Supervision, writing of paper original and revised draft. M.S., G.S.K., M.G.S. and M.Z. equally contributed in formal analysis; Software; Writing-review and editing, A.N. collected Crystal data, visualization; R.U. Characterization of samples, help in write up, revisions and funding acquisition, A.B. Characterization of samples, help in write up, revisions and funding acquisition. All authors have read and agreed to the published version of the manuscript.

Funding: This research was funded by King Saud University Research Supporting Project Number: RSP-2021/346.

Institutional Review Board Statement: Not applicable.

Informed Consent Statement: Not applicable.

Data Availability Statement: Data which support this work is included in the manuscript.

Acknowledgments: Authors wish to thanks Research Supporting Project Number: RSP-2021/346 King Saud University Riyadh Saudi Arabia for their financial support.

Conflicts of Interest: The authors declare no conflict of interest.

\section{References}

1. Rahman, F.U.; Bibi, M.; Khan, E.; Shah, A.B.; Muhammad, M.; Tahir, M.N.; Shahzad, A.; Ullah, F.; Zahoor, M.; Alamery, S.; et al. Thiourea Derivatives, Simple in Structure but Efficient Enzyme Inhibitors and Mercury Sensors. Molecules 2021, $26,4506$. [CrossRef] [PubMed]

2. Khan, E.; Khan, S.; Gul, Z.; Muhammad, M. Medicinal Importance, Coordination Chemistry with Selected Metals (Cu, Ag, Au) and Chemosensing of Thiourea Derivatives. A Review. Crit. Rev. Anal. Chem. 2021, 1-23. [CrossRef] 
3. Zhang, Z.; Schreiner, P.R. (Thio)urea organocatalysis-What can be learnt from anion recognition? Chem. Soc. Rev. 2009, 38, 1187-1198. [CrossRef] [PubMed]

4. Sun, Y.; Wei, Y.; Shi, M. Applications of Chiral Thiourea-Amine/Phosphine Organocatalysts in Catalytic Asymmetric Reactions. ChemCatChem 2017, 9, 718-727. [CrossRef]

5. Esteban, F.; Cieślik, W.; Arpa, E.M.; Guerrero-Corella, A.; Díaz-Tendero, S.; Perles, J.; Fernandez-Salas, J.A.; Fraile, A.; Alemán, J. Intramolecular Hydrogen Bond Activation: Thiourea-Organocatalyzed Enantioselective 1,3-Dipolar Cycloaddition of Salicylaldehyde-Derived Azomethine Ylides with Nitroalkenes. ACS Catal. 2018, 8, 1884-1890. [CrossRef] [PubMed]

6. Steppeler, F.; Iwan, D.; Wojaczyńska, E.; Wojaczyński, J. Chiral Thioureas-Preparation and Significance in Asymmetric Synthesis and Medicinal Chemistry. Molecules 2020, 25, 401. [CrossRef]

7. Li, A.-F.; Wang, J.-H.; Wang, F.; Jiang, Y.-B. Anion complexation and sensing using modified urea and thiourea-based receptors. Chem. Soc. Rev. 2010, 39, 3729-3745. [CrossRef]

8. Bregović, V.B.; Basaric, N.; Mlinarić-Majerski, K. Anion binding with urea and thiourea derivatives. Coord. Chem. Rev. 2015, 295, 80-124. [CrossRef]

9. Udhayakumari, D.; Velmathi, S.; Venkatesan, P.; Wu, S.-P. Anthracene coupled thiourea as a colorimetric sensor for $\mathrm{F}^{-} / \mathrm{Cu}^{2+}$ and fluorescent sensor for $\mathrm{Hg}^{2+}$ / picric acid. J. Lumin. 2015, 161, 411-416. [CrossRef]

10. Zhang, Z.; Lu, S.; Sha, C.; Xu, D. A single thiourea-appended 1,8-naphthalimide chemosensor for three heavy metal ions: Fe ${ }^{3+}$, $\mathrm{Pb}^{2+}$, and $\mathrm{Hg}^{2+}$. Sens. Actuators B Chem. 2015, 208, 258-266. [CrossRef]

11. Koch, K.R. New chemistry with old ligands: N-alkyl- and N,N-dialkyl-N'-acyl(aroyl)thioureas in co-ordination, analytical and process chemistry of the platinum group metals. Coord. Chem. Rev. 2001, 216-217, 473-488. [CrossRef]

12. Saeed, A.; Qamar, R.; Fattah, T.A.; Flörke, U.; Erben, M.F. Recent developments in chemistry, coordination, structure and biological aspects of 1-(acyl/aroyl)-3-(substituted) thioureas. Res. Chem. Intermed. 2016, 43, 3053-3093. [CrossRef]

13. Reddy, V.L.; Avula, V.K.R.; Zyryanov, G.V.; Vallela, S.; Anireddy, J.S.; Pasupuleti, V.R.; Chamarthi, N.R. Hunig's base catalyzed synthesis of new 1-(2,3-dihydro-1H-inden-1-yl)-3-aryl urea/thiourea derivatives as potent antioxidants and 2HCK enzyme growth inhibitors. Bioorganic Chem. 2020, 95, 103558. [CrossRef] [PubMed]

14. Thomas, S.J.; Balónová, B.; Cinatl, J.; Wass, M.; Serpell, C.J.; Blight, B.A.; Michaelis, M. Thiourea and Guanidine Compounds and Their Iridium Complexes in Drug-Resistant Cancer Cell Lines: Structure-Activity Relationships and Direct Luminescent Imaging. ChemMedChem 2019, 15, 349-353. [CrossRef]

15. Hu, H.; Lin, C.; Ao, M.; Ji, Y.; Tang, B.; Zhou, X.; Fang, M.; Zeng, J.-Z.; Wu, Z. Synthesis and biological evaluation of 1-(2(adamantane-1-yl)-1H-indol-5-yl)-3-substituted urea/thiourea derivatives as anticancer agents. RSC Adv. 2017, 7, 51640-51651. [CrossRef]

16. Ghorab, M.M.; El-Gaby, M.; Alsaid, M.S.; Elshaier, Y.; Soliman, A.M.; Elsenduny, F.; Badria, F.A.; Sherif, A.Y. Novel Thiourea Derivatives Bearing Sulfonamide Moiety as Anticancer Agents Through COX-2 Inhibition. Anti-Cancer Agents Med. Chem. 2017, 17, 1411-1425. [CrossRef] [PubMed]

17. Estévez-Hernández, O.; Duque, J.; Rodríguez-Hernández, J.; Reguera, E. Dinuclear and polymeric Hg(II) complexes with 1-(2-furoyl)thiourea derivatives: Their crystal structure and related properties. Polyhedron 2015, 97, 148-156. [CrossRef]

18. Cole, J.M.; Hickstein, D.D. Molecular origins of nonlinear optical activity in zinc tris (thiourea) sulfate revealed by high-resolution x-ray diffraction data and ab initio calculations. Phys. Rev. B 2013, 88, 184105. [CrossRef]

19. Shkir, M.; Ganesh, V.; AlFaify, S.; Maurya, K.K.; Vijayan, N. Effect of phenol red dye on monocrystal growth, crystalline perfection, and optical and dielectric properties of zinc (tris) thiourea sulfate. J. Appl. Crystallogr. 2017, 50, 1716-1724. [CrossRef]

20. Chetana, P.; Srinatha, B.; Somashekar, M.; Policegoudra, R. Synthesis, spectroscopic characterisation, thermal analysis, DNA interaction and antibacterial activity of copper(I) complexes with N, N'- disubstituted thiourea. J. Mol. Struct. 2016, 1106, 352-365. [CrossRef]

21. Mahendiran, D.; Amuthakala, S.; Bhuvanesh, N.S.P.; Kumar, R.S.; Rahiman, A.K. Copper complexes as prospective anticancer agents: In vitro and in vivo evaluation, selective targeting of cancer cells by DNA damage and S phase arrest. RSC Adv. 2018, 8, 16973-16990. [CrossRef]

22. Jose, E.S.; Philip, J.E.; Shanty, A.; Kurup, M.; Mohanan, P. Novel class of mononuclear 2-methoxy-4-chromanones ligated Cu (II), Zn (II), Ni (II) complexes: Synthesis, characterisation and biological studies. Inorganica Chim. Acta 2018, 478, 155-165. [CrossRef]

23. Iliş, M.; Cîrcu, V. Discotic Liquid Crystals Based on Cu (I) Complexes with Benzoylthiourea Derivatives Containing a Perfluoroalkyl Chain. J. Chem. 2018, 2018, 1-10. [CrossRef]

24. Khan, S.A.; Noor, A.; Kempe, R.; Subhan, H.; Shah, A.; Khan, E. Syntheses, molecular structure, and electrochemical investigations of cobalt (II), copper (II), palladium (II), and zinc (II) complexes with 3-methylpyrazole. J. Coord. Chem. 2014, 67, 2425-2434. [CrossRef]

25. Khan, E.; Shahzad, A.; Tahir, M.N.; Noor, A. Antioxidant potential and secondary reactivity of bis\{diphenyl(2-pyridyl)phosphino\} copper (II) complex. Turk. J. Chem. 2018, 42, 1299-1309. [CrossRef]

26. Khan, E.; Gul, Z.; Shahzad, A.; Jan, M.S.; Ullah, F.; Tahir, M.N.; Noor, A. Coordination compounds of 4,5,6,7-tetrahydro-1Hindazole with $\mathrm{Cu}(\mathrm{II}), \mathrm{Co}(\mathrm{II})$ and $\mathrm{Ag}(\mathrm{I})$ : Structural, antimicrobial, antioxidant and enzyme inhibition studies. J. Coord. Chem. 2017, 70, 4054-4069. [CrossRef] 
27. Gul, Z.; Din, N.U.; Khan, E.; Ullah, F.; Tahir, M.N. Synthesis, molecular structure, anti-microbial, anti-oxidant and enzyme inhibition activities of 2-amino-6-methylbenzothiazole and its $\mathrm{Cu}(\mathrm{II})$ and $\mathrm{Ag}(\mathrm{I})$ complexes. J. Mol. Struct. 2020, $1199,126956$. [CrossRef]

28. Rahman, F.U.; Bibi, M.; Altaf, A.A.; Tahir, M.N.; Ullah, F.; Khan, E. Zn, Cd and Hg complexes with unsymmetric thiourea derivatives; syntheses, free radical scavenging and enzyme inhibition essay. J. Mol. Struct. 2020, 1211, 128096. [CrossRef]

29. Khan, U.A.; Badshah, A.; Tahir, M.N.; Khan, E. Gold (I), silver (I) and copper (I) complexes of 2, 4, 6-trimethylphenyl-3benzoylthiourea; synthesis and biological applications. Polyhedron 2020, 181, 114485. [CrossRef]

30. Altaf, A.A.; Shahzad, A.; Gul, Z.; Khan, S.A.; Badshah, A.; Tahir, M.N.; Zafar, Z.I.; Khan, E. Synthesis, Crystal Structure, and DFT Calculations of 1,3-Diisobutyl Thiourea. J. Chem. 2015, 2015, 1-5. [CrossRef]

31. Altomare, A. A new tool for crystal structure determination and refinement. J. Appl. Cryst. 1994, 27, 435. [CrossRef]

32. Sheldrick, G.M. Crystal structure refinement with SHELXL. Acta Crystallogr. Sect. C Struct. Chem. 2015, 71, 3-8. [CrossRef] [PubMed]

33. Farrugia, L.J. WinGX suite for small-molecule single-crystal crystallography. J. Appl. Crystallogr. 1999, 32, 837-838. [CrossRef]

34. Farrugia, L.J. ORTEP-3 for Windows-A version ofORTEP-III with a Graphical User Interface (GUI). J. Appl. Crystallogr. 1997, 30, 565. [CrossRef]

35. Spek, A.L. Structure validation in chemical crystallography. Acta Crystallogr. Sect. D Biol. Crystallogr. 2009, 65, 148-155. [CrossRef] [PubMed]

36. Khan, E.; Khan, A.; Gul, Z.; Ullah, F.; Tahir, M.N.; Khalid, M.; Asif, H.M.; Asim, S.; Braga, A.A.C. Molecular salts of terephthalic acids with 2-aminopyridine and 2-aminothiazole derivatives as potential antioxidant agents; Base-Acid-Base type architectures. J. Mol. Struct. 2020, 1200, 127126. [CrossRef]

37. Irshad, S.; Mahmood, M.; Perveen, F. In vitro antibacterial activities of three medicinal plants using agar well diffusion method. Res. J. Biol. 2012, 2, 1-8.

38. Athanassiadis, B.; Abbott, P.V.; George, N.; Walsh, L.J. An in vitro study of the antimicrobial activity of some endodontic medicaments and their bases using an agar well diffusion assay. Aust. Dent. J. 2009, 54, 141-146. [CrossRef]

39. Mufakkar, M.; Isab, A.A.; Rüffer, T.; Lang, H.; Ahmad, S.; Arshad, N.; Waheed, A. Synthesis, characterization, and antibacterial activities of copper (I) bromide complexes of thioureas: X-ray structure of [Cu (Metu) 4] Br. Transit. Met. Chem. 2011, 36, 505-512. [CrossRef]

40. Bombicz, P.; Mutikainen, I.; Krunks, M.; Leskelä, T.; Madarász, J.; Niinistö, L. Synthesis, vibrational spectra and X-ray structures of copper(I) thiourea complexes. Inorganica Chim. Acta 2004, 357, 513-525. [CrossRef]

41. Bowmaker, G.A.; Hanna, J.V.; Pakawatchai, C.; Skelton, B.; Thanyasirikul, Y.; White, A.H. Crystal Structures and Vibrational Spectroscopy of Copper (I) Thiourea Complexes. Inorg. Chem. 2009, 48, 350-368. [CrossRef] [PubMed]

42. Malik, M.R.; Vasylyeva, V.; Merz, K.; Metzler-Nolte, N.; Saleem, M.; Ali, S.; Isab, A.A.; Munawar, K.S.; Ahmad, S. Synthesis, crystal structures, antimicrobial properties and enzyme inhibition studies of zinc (II) complexes of thiones. Inorganica Chim. Acta 2011, 376, 207-211. [CrossRef]

43. Ajibade, P.A.; Zulu, N.H. Metal Complexes of Diisopropylthiourea: Synthesis, Characterization and Antibacterial Studies. Int. J. Mol. Sci. 2011, 12, 7186-7198. [CrossRef]

44. Saxena, A.; Dugan, E.C.; Liaw, J.; Dembo, M.D.; Pike, R.D. Copper (I) complexes of heterocyclic thiourea ligands. Polyhedron 2009, 28, 4017-4031. [CrossRef]

45. Zhao, X.-Y.; Zhu, C.-B.; Li, H.-P.; Yang, Y.; Roesky, H.W. Synthesis and Characterization of Copper (I) Halide Complexes withN-(2, 6-Diisopropylphenyl)-N'-benzoylthiourea: Monomeric, Dimeric, and Cage Structures. Z. Für Anorg. Und Allg. Chem. 2014, 640, 1614-1621. [CrossRef]

46. Jia, D.; Zhu, A.M.; Ji, M.; Zhang, Y. Copper (I) halide complexes with a sterically hindered thiourea: Synthesis and crystal structures of $\left[\mathrm{Cu}(\mathrm{dchtu})_{2} \mathrm{Cl}\right]$ and $\left[\mathrm{Cu}(\mathrm{dchtu})_{2} \mathrm{Br}\right]\left(\mathrm{dchtu}=\mathrm{N}, \mathrm{N}^{\prime}\right.$-dicyclohexylthiourea). J. Coord. Chem. 2008, 61, 2307-2314. [CrossRef]

47. Piro, O.E.; Piatti, R.C.V.; Bolzan, A.E.; Salvarezza, R.C.; Arvia, A.J. X-ray diffraction study of copper (I) thiourea complexes formed in sulfate-containing acid solutions. Acta Crystallogr. Sect. B Struct. Sci. 2000, 56, 993-997. [CrossRef]

48. Pakawatchai, C.; Thanyasirikul, Y.; Saepae, T.; Pansook, S.; Fun, H.-K.; Chinnakali, K. Hexakis ( $\mu$-N-ethylthiourea-S) tetrakis [iodocopper (I)] Monohydrate. Acta Crystallogr. Sect. C Cryst. Struct. Commun. 1998, 54, 1750-1752. [CrossRef]

49. McNelis, E.; Blandino, M. 657, a method for estimating tetrahedral bond angles. New J. Chem. 2001, 25, 772-774. [CrossRef]

50. Ahmad, S.; Altaf, M.; Stoeckli-Evans, H.; Rüffer, T.; Lang, H.; Mufakkar, M.; Waheed, A. Crystal Structures of Trinuclear Chlorido $\left(\mathrm{N}, \mathrm{N}^{\prime}\right.$-diethylthiourea) copper (I) and a Second Polymorph of Iodidotris ( $\mathrm{N}, \mathrm{N}^{\prime}$-diethylthiourea) copper (I). J. Chem. Crystallogr. 2010, 40, 639-645. [CrossRef]

51. Fun, H.K.; Razak, I.A.; Pakawatchai, C.; Khaokong, C.H.U.A.N.P.I.T.; Chantrapromma, S.; Saithong, S.A.P.W.A.N.I.T. Tris (N,N'-diethylthiourea-S) iodocopper (I) and Tris (N,N'-diethylthiourea-S) iodosilver (I). Acta Crystallogr. Sect. C Cryst. Struct. Commun. 1998, 54, 453-456. [CrossRef]

52. Binzet, G.; Kavak, G.; Külcü, N.; Özbey, S.; Flörke, U.; Arslan, H. Synthesis and Characterization of Novel Thiourea Derivatives and Their Nickel and Copper Complexes. J. Chem. 2013, 2013, 1-9. [CrossRef] 